\title{
The Thumbprint of a Hybrid Organization-A Multidimensional Model for Analysing Public/Private Hybrid Organizations
}

\author{
Philip Marcel Karré ${ }^{1}$
}

Accepted: 12 December 2021

(c) The Author(s) 2022

\begin{abstract}
Hybridity has become a widely-used concept in public management theory and practice. Yet, there is limited insight in what constitutes a hybrid organization. This article argues that it is not enough to say an organization is hybrid; you need to say how an organization is hybrid, as organizations can mix the characteristics of state and market on several dimensions and with differing intensities. They all have, as it were, a distinctive hybrid thumbprint, which can influence an organization's performance and hence the quality of its service provision. Therefore, a model is presented to visualize this unique thumbprint.
\end{abstract}

Keywords Hybrid organization · Government agency · State-owned enterprise · Organizational hybridity $\cdot$ Multidimensional model

\section{Introduction}

More and more organizations operate in the fuzzy world between the public and the private realm. These hybrid organizations straddle the borders between the seemingly distinct spheres of the market, state, and civil society, each characterized by a unique set of dominant norms, values and institutional logics and template for organizing (Anheier \& Krlev, 2015; Billis \& Rochester, 2020; Brandsen \& Karré, 2021; Grossi et al., 2017; Powell et al., 2019; Schmitz \& Glänzel, 2016; Smith, 2014). Hybrid organizations combine the characteristics and logics conventionally attached to public, private and Third sector organizations (Anheier \& Krlev, 2015; Battilana \& Lee, 2014; Billis, 2010b; Brandsen et al., 2005; Brandsen \& Karré, 2011; Denis et al., 2015; Jay, 2012; Johanson \& Vakkuri, 2018; Schmitz \& Glänzel, 2016; Skelcher \& Smith, 2015; Vakkuri \& Johanson, 2021; Vakkuri et al., 2021). By doing so,

Philip Marcel Karré

karre@essb.eur.nl

1 Department of Public Administration and Sociology, Erasmus University Rotterdam, Room T17-20, P.O. Box 1738, 3000 DR Rotterdam, The Netherlands 
they "(1) involve a variety of stakeholders, (2) pursue multiple and often conflicting goals, (3) engage in divergent or inconsistent activities." (Mair et al., 2015, p. 714).

There are several types of hybrid organizations, depending on which sector they originally originate from and depending on which sectoral characteristics they are mixing (Billis, 2010b, p. 57). This article focusses on public/private hybrid organizations between state and market. Examples include state-owned enterprises, agencies, and other forms of quasi-non-governmental organizations (or quangos) that not only operate at arm's length from their political masters but also undertake commercial activities on behalf of government (Bruton et al., 2015; Karré, 2011; Pollitt \& Talbot, 2004; Pollitt et al., 2004; van Thiel, 2000).

Such public/private hybrid organizations have a long history as agents in public service provision, as many countries have moved from the 'welfare state' to a 'welfare mix' (Defourny, 2014, p. 20; Seibel, 2015), in which the set, predictable blueprint for organisations providing public services - if such a thing ever existed - has become less prevalent (Brès et al., 2018; Christensen \& Lægreid, 2010; Giauque et al., 2014). However, several authors argue that hybrid organizations are undertheorized in public administration and non-profit literature and that the concept of hybridity is mainly used here as a descriptor and umbrella term for organizations with two or more sectoral characteristics (Billis, 2010a; Denis et al., 2015; Johanson \& Vakkuri, 2018; Skelcher \& Smith, 2015). In the words of Skelcher and Smith (2015, p. 434) "the field still lacks a clear theoretical foundation that can explain what it is that creates a hybrid, whether different forms of hybrids emerge in different situations, and if so what consequences arise".

This lack of theory is problematic: we might be able to describe hybrid organizations in rather general terms as a mixture of public and private sector characteristics, but without insight into how they are hybrid, i.e. on which dimensions that mix takes place, not much can subsequently be said about the effects of their hybridity and whether this has (or has not) an effect on their performance and therefore on how well (or not) they do in providing public services. So, a first step in getting a firmer grip on hybridity should be to develop a better understanding of the multidimensional character of hybrid organizations.

This article addresses this point by presenting a multidimensional model of public/private hybrid organizations. It answers the following research question: on which dimensions can an organization be a hybrid at the nexus of state and market and how can this hybridity be visualized? By doing so, this article adds to our conceptual understanding of hybridity in organizations between state and market. The model will show that there is a myriad of different forms of public/private hybrid organizations, each with a distinctive hybrid thumbprint. It can be used to assess the hybrid character of an individual hybrid organization and distinguish it from others. It can also be used to look at organizations' hybrid character at various points in time and to see how and why their hybridity changed. Analysing the hybrid thumbprint of an organization can help to understand and perhaps enhance its performance and hence is not only a valuable exercise for organizational theorists but also for practitioners.

The idea that hybridity is a multidimensional phenomenon is of course not per se new and there already are several multidimensional models. But the literature on 
hybridity is fragmented, description of the dimensions of hybridity often limited and not all available models use the same dimensions. What the model presented in this article adds, is that it (1) focusses on developing and describing the dimension on which an organization can be hybrid, (2) that it combines and synthesizes the insights from other models, so that hybridity can be understood in a more holistic, all-encompassing way and (3) that it also proposes a way to visualize how an organization can be scored on each of these dimensions. While the model does not claim that hybridity can unambiguously be 'measured' and hence quantified on all these dimensions, deciding where an organization fits on a given dimension at any moment in time, can be a valuable exercise to further understand and discuss its hybrid character.

A first version of the multidimensional model was mostly based on classic studies on the differences between public and private organizations (Bozeman, 1987; Dahl \& Lindblom, 1953; Fottler, 1981; Hood, 1991; Jacobs, 1992; Lane, 1994; Perry \& Rainey, 1988; Rainey, 1997; Rainey \& Chun, 2007; Wamsley \& Zald, 1973). Since then, more literature has become available that deals explicitly with hybrid organizations and their dimensions (e.g., Alexius \& Furusten, 2019; Anheier \& Krlev, 2015; Battilana \& Lee, 2014; Billis, 2010b; Brandsen \& Karré, 2021; Johanson \& Vakkuri, 2018; Mair et al., 2015; Powell et al., 2019; Vakkuri et al., 2021). Insights from this literature have been added to the model. This exercise has also led to a critical reassessment of the earlier model and the decision to drop three of the earlier ten dimensions, as they (in hindsight) could not be measured by degrees but rather were either/or choices: 'legal form' (based either on public or on private law), 'market environment' (either monopolistic or competitive) and 'relationship with public principal' (again either based on public or on private law). Furthermore, two dimensions dealing with autonomy ('managerial autonomy' and 'executive autonomy') were merged as in hindsight differentiating between the two did not seem to be practical anymore.

This article is structured as follows: it will first focus on the perceived differences between the state and the marketplace as realms of society and between the public and private organizations that inhabit these sectors. It will describe that, rather than as a dichotomy, state and market should be seen as the extremes of a continuum and that in this continuum organizations can mix the characteristics of the public and the private sector on several dimensions. Each of these dimensions will be presented in turn and then brought together in a multidimensional model of a public/ private hybrid organization. In order to show how this model works in practice and the added value it can bring to understanding an organization's hybridity, its use will be illustrated by applying it to a hybrid organization in the Dutch waste management sector. This article ends with a discussion of its main conclusions.

\section{Differences Between Ideal-Typical Public and Private Organizations}

Public and private organizations differ from one another in several ways. According to Rainey and Chun (2007), who have reviewed the vast literature on this subject, public sector organizations differ from private sector organizations regarding 
their (1) environment, (2) organization-environment transactions and (3) organizational roles, structures and processes.

The first set of differences concern the specific setting or environment public sector organizations operate in (Rainey \& Chun, 2007, pp. 80-81). They are not active on the marketplace but rely on government appropriations. Because of this, they must submit to greater political and administrative scrutiny, more intensive external political influences, more government oversight and greater legal constraints than private sector organizations.

A second set of differences between public and private sector organizations as identified by Rainey and Chun (2007, p. 81), concern the transactions between the organization and its environment. Public organizations produce public goods that are not readily transferable to economic markets at a market price. Public organizations often play a special part in society, as government activities in general are often coercive, monopolistic, and unavoidable. Because they deal with the production of public values and must be seen to act in the public interest, they have to adhere to values such as fairness, responsiveness, honesty, openness and accountability in their relations with the outside world.

A final set of differences between public sector and private sector organizations Rainey and Chun (2007, pp. 82-86) collected, relates to organizational roles, structures, and processes. Public sector organizations must deal with greater ambiguity, multiplicity, and conflict than their private sector counterparts. Their managers have to play more political, expository roles, which results in a greater challenge to balance external political relations with internal management functions. Often, they also have lesser autonomy than their counterparts in private sector organizations to take strategic and executive decisions. The employees of public sector organizations are said to have different work-related values than private sector workers, such as a lower valuation of monetary incentives and higher levels of public service motivation. Public sector organizations are also said to have more red tape and more elaborate bureaucratic structures than private sector organizations, leading to a culture of caution and a lack of innovation and efficiency. Greater administrative constraints on the administration of extrinsic incentives (pay, promotion) and weaker relations between performance and extrinsic rewards (pay, promotion, job security), can lead to lower levels of work satisfaction and organizational commitment.

Such a description of differences between public sector and private sector organizations might give the impression that there is a dichotomy between the two. Several authors warn against adopting such a position, which is useful for normative discussions but less so for descriptive purposes (Bozeman, 1987; Dahl \& Lindblom, 1953; Geuss, 2001; Rainey \& Chun, 2007; Skelcher, 2005). In practice, there is a continuum between the two, as there are several patterns of government-market interrelations (a point already made by Dahl and Lindblom; see Rainey, 1997, p. 65). In the last decades, especially New Public Management (NPM) (Christensen \& Lægreid, 2011a, b; McLaughlin et al., 2002; Pollitt et al., 2007) with its credo to 'run government like a business' (Osborne \& Gaebler, 1992) has led to a further erosion of the borders between state and market and hence to the emergence of hybrid organisations that mix characteristics of public and private sector organizations. 
In order to understand the state and market distinction not as a dichotomy but as a continuum, it is necessary to identify several dimensions on which an organization can mix the characteristics of public sector and private sector organizations, i.e., the dimensions on which it is a hybrid. These dimensions will be presented in the next section.

\section{Dimensions of Hybridity}

As described earlier, a study of classic literature on differences between public and private organizations and of the emerging literature on public/private hybrid organizations, led to the identification of the following six dimensions of hybridity: (1) ownership, (2) activities, (3) funding, (4) value orientation, (5) strategic orientation, (6) autonomy. Below, each of them will be presented in turn:

\section{Ownership}

The first dimension deals with who the proprietor of the organization is (Alexius \& Furusten, 2019; Billis, 2010b; Dahl \& Lindblom, 1953; Grossi et al., 2017; Perry \& Rainey, 1988; Vakkuri et al., 2021; Wamsley \& Zald, 1973). In the private sector, organizations are commonly owned by private shareholders. In the public sector, organizations are owned by the state (and in extension citizens). Hence this dimension deals with the continuum between full governmental and full private ownership. In case of privatisation, typically the legal form will be changed first, and then shares will be sold off in tranches, transferring (part) ownership from public to private hands in one or more steps.

\section{Activities}

This dimension concerns the activities the organization undertakes and is the continuum between a complete focus on public, often statutory tasks which the organization undertakes on behalf of government and one on private, commercial activities, for which the organization has to find a buyer on the marketplace (Battilana \& Lee, 2014; Fottler, 1981; Grossi et al., 2017; Powell et al., 2019). Another way to look at this dimension, is to look at the customers of the organisation's goods or services. For a public organization, those are governments, who purchase goods and services on behalf of citizens. Private organizations, in contrast, directly deal with the end user. Hybrid organizations will have a mixed clientele, as they conduct different activities (Mair et al., 2015, p. 714).

\section{Funding}

Public and private sector organizations differ with regard to funding: private organizations generate their funding through earnings from commercial activities and public organizations receive money government has levied through taxation (Alexius \& 
Furusten, 2019; Anheier \& Krlev, 2015; Billis, 2010b; Fottler, 1981; Grossi et al., 2017; Perry \& Rainey, 1988; Vakkuri et al., 2021; Wamsley \& Zald, 1973). Hence, this is the continuum between $100 \%$ governmental appropriation and $100 \%$ private funding. This dimension is closely related to the previous dimension of activities, but differs, as under NPM public organizations now also have to compete with each other for funds for statutory activities.

\section{Value Orientation}

This dimension is the one between an orientation on public and an orientation on private values (Battilana \& Lee, 2014; Powell et al., 2019), as several authors state that there are differences between the core values of public and of private sector organizations (Jacobs, 1992; Lane, 1994; van der Wal \& van Hout, 2009; van der Wal et al., 2008) and between the institutional logics at play in both sectors (Thornton et al., 2012; Vakkuri \& Johanson, 2021; Vakkuri et al., 2021). This is the continuum between a full focus on what traditionally are seen as the public sector institutional logic (based on values such as public service motivation, bureaucracy, rules) and a full focus on what traditionally is seen as the private sector institutional logic (based on values such as profit motive, innovation, efficiency).

\section{Strategic Orientation}

This dimension deals with the organization's main purpose or organizational priorities and their translation into strategy (Alexius \& Furusten, 2019; Anheier \& Krlev, 2015; Billis, 2010b; Grossi et al., 2017; Joldersma \& Winter, 2002; Vakkuri et al., 2021). This is the continuum between a strategic focus on administration and the service of public benefits and one on profits and dividends to shareholders. This again is closely related to the previous dimension of activities but differs from this as it deals with the overall strategy of the organization, not only the activities it undertakes to fulfil this purpose. For example, an organization can use activities on behalf of governments to generate profits and dividends for shareholders, e.g., arms manufacturers.

\section{Autonomy}

This last dimension deals with the level of autonomy the management of the organization has on strategic issues (e.g., Grossi et al., 2017; Vakkuri et al., 2021). Bozeman (1987) describes this as the continuum between political and economic authority, i.e., between none and full autonomy of the managers of an organization to determine its strategy. Public organizations operate on behalf of government and are under political scrutiny and influence. Their managers hence do not have much autonomy to devise their own strategy, whereas in private sector organizations managers have high degrees of autonomy to decide on strategic issues. With this we mean the autonomy to specify the organisation's objectives, translate them into policies and plans and to allocate resources to implement them. Therefore, this is the 
continuum between an organization's management with no autonomy whatsoever (everything is dictated by the public principal) and one with full autonomy to devise the organization's long-term strategic outlook at their own accord.

\section{Multi-Dimensional Model of a Hybrid Organization}

The preceding section described the dimensions on which a hybrid organization can be a mixture of the characteristics of public sector and private sector organizations. The reason different dimensions are used is that generally, hybrid organizations do not mix these characteristics on all dimensions simultaneously and also not necessarily to the same extent or with the same intensity. For example, it is very well possible for an organization to be fully owned by government and at the same time engage in commercial activities, as is the case with many state-owned enterprises.

In this section, we combine the six dimensions into a multidimensional model of a hybrid organization. By combining the dimensions in a radar chart, it is possible to illustrate the hybrid thumbprint of an organization at a certain point in time. Thumbprints taken at different moments can be used to illustrate the development of an organization to more or less hybridity or to another form of hybridity and can serve as starting points for discussions on whether and how this has influenced its performance.

To map a hybrid organization in this way, it is necessary not only to devise dimensions on which an organization can be a hybrid but to also devise a method of scoring their hybridity. In this, the multidimensional model presented here shares some characteristics with the comparative method known as Qualitative Comparative Analysis (QCA), which turns qualitative dimensions into quantifiable information (Ragin, 2009, 2010).

Of course, scoring an organization on these dimensions is no exact science. More often than not, lines between exactly what is public and what is private will be blurry rather than sharp, so in most cases the scale from 0 (completely public) to 10 (completely private) should be understood to go from more fuzzy values, e.g., 2 (mostly public), 4 (somewhat public), 5 (halfway between public and private), 6 (somewhat private) and 8 (mostly private). Where lines are blurry, the importance of not looking at one snapshot (and figuring out what exactly is meant by a score of 4?) but rather the comparison of two or more points in time becomes even more crucial, in which it is the shift away from public and towards private that is expressed in a change of score from 4 to 6 that is relevant, rather than the exact meaning of either of those scores.

A hypothetical organization, represented as only a dot at the centre of the chart, would be $100 \%$ public on all the dimensions featured before. As the surface area grows, the organization becomes more private to the maximum of covering the full chart, which represents an organization that scores $100 \%$ private on all dimensions: the ideal-typical enterprise. A prototypical hybrid organization would be half public sector organization/half private sector organization and could be visualized as portrayed in Fig. 1. 
Fig. 1 Ideal-typical hybrid organization

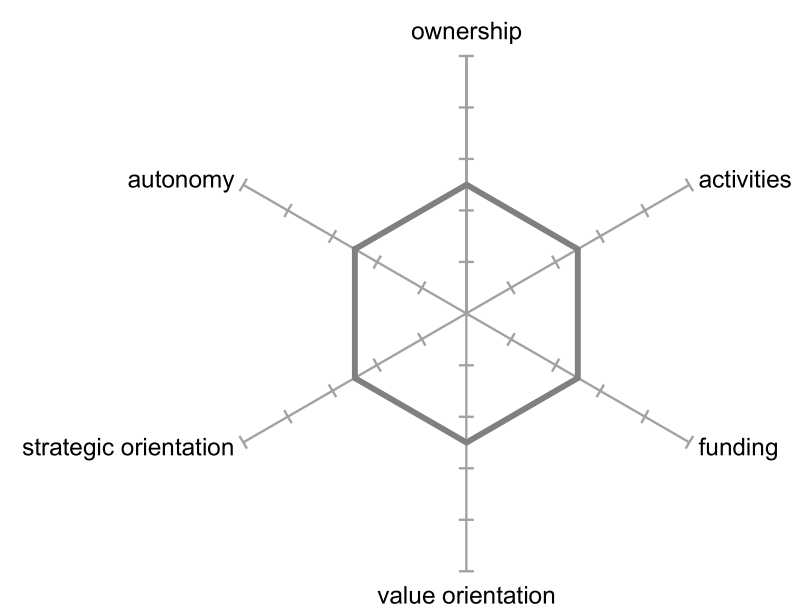

However, reality is far messier and such perfect hybrids are only rarely to be found. Most hybrid organizations do not score evenly on all dimensions but rather show heterogeneous scores. We will illustrate this in the next section by applying the model to a hybrid organization from the Dutch waste management sector at two different moments in time.

\section{Example for the Application of the Model}

The multidimensional model presented here was used while doing research on hybrid organizations active in the Dutch waste management sector. This was done to establish whether and how the model would work in practice and to refine it.

Waste management is an important activity with several public interests at stake, especially with regard to public and environmental health. That is why, in the Netherlands, the waste management sector used to be heavily regulated. Waste was predominantly collected by government-owned collection services, which had to dispose of it at landfill sites or incineration plants which also were publicly owned. In the early 2000s the waste management sector was deregulated, and market forces were introduced. However, especially local authorities still have a significant stake in the market, by often still running their own waste collection services. Also, some incineration plants are in public hands still.

One of the waste management companies that were examined using the multidimensional model, was one of these publicly-held waste incineration companies. At the time of this research, the organization's managing director had recently been given more autonomy to run the organization like a business. This made it possible to apply the multidimensional model to assess the hybrid character of the organization at two moments in time, before and after this step, in order to get a better insight in how the organization was hybrid and how its hybridity changed over time. The insights from this exercise were also discussed with the organization and used 
by its management to reflect on its further plans with regard to the organization's development.

Albeit slightly outdated, this case is presented here mainly as an illustration for how the multidimensional model can be used in research and practice. In order to establish how the organization could be scored on the ten dimensions of the model, 15 semi-structured interviews were held with the organizations' management, members of its supervisory and work-relations councils and with its contacts at the municipality that owned it, both at the political (aldermen) as well as on the administrative level (civil servants). Also, relevant documents were studied, such as annual reports and internal documents and memos. Finally, relevant meetings were observed, such as those of the supervisory boards and shareholder meetings. In order to test their internal validity, the findings were compiled into a case study report that was presented to and discussed with the organization's managers. The findings from this and two other waste management organizations studied the same way, were also presented to a panel of directors of other hybrid waste management organizations in order to test their external validity and representativeness.

The waste incineration company under discussion here was owned by one of the Netherlands' biggest municipalities and burnt waste from households and businesses. Before the organization's managing director was granted more freedom to run the organization in a more business-like manner, about $60 \%$ of the waste it burnt originated from households and had been collected by various municipal waste collection services. The other $40 \%$ were waste from businesses, which had been collected by a commercial company. The reason for also incinerating waste from businesses, were mainly technical, as it helped the organization to make sure that its ovens were always fully utilized. The organization had long-term contracts with all its customers. There was a certain element of competition, as these contracts had to be renegotiated from time to time but as there was no serious competition in general the organization enjoyed a near-monopolistic market position. It mostly focussed on the technological aspects of waste incineration and, even though some employees showed limited entrepreneurial behaviour, in general it lacked an entrepreneurial orientation.

As a municipal enterprise, the organization was an integral part of the municipality's structure and had the same bureaucratic structure and culture as the municipality. An alderman was ultimately responsible and the municipality liable for how the organization conducted its business. On paper, the organization's managing director had no autonomy of his own but was expected to follow the orders he received from town hall. In reality, he of course had far more autonomy, mainly due to the specialist nature of waste incineration and the fact that waste management was not very high on the alderman's list of priorities. But this autonomy had no formal status and could be rescinded at a moment's notice.

Figure 2 shows how the organization scored on the dimensions of the model at this point in time. It is scored completely public on most and mostly or somewhat public on some categories, as it also had some market activities (incineration of business waste) and hence generated some commercial income, though both were mainly a side-line to its municipal activities (incinerating household waste), which were seen as far more important. Some of the organization's employees showed 
Fig. 2 The waste incineration organization before hybridization

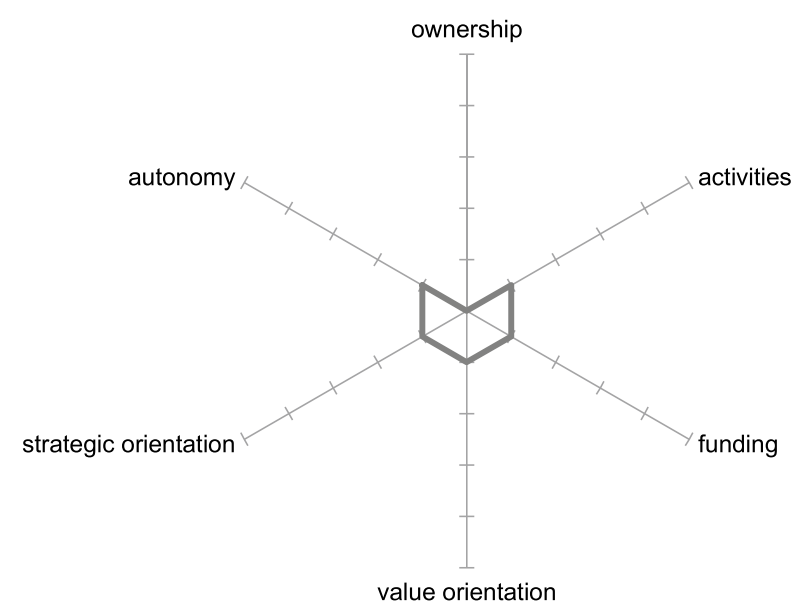

limited entrepreneurial behaviour and it also had to take its commercial customers' wishes into account, but this did not account for much. While de jure the organization's managing director had no autonomy, de facto he could make some decisions completely on his own, albeit only on minor details when things were going well.

After several years of lobbying, the municipality finally granted the managing director more autonomy to run what he saw as "his" organization like a business. This formalised the status quo in which this director already had more autonomy in reality than on paper. However, the municipality decided against putting the organization at arm's length as well, which meant that while its managing director had a lot more autonomy now, the organization itself remained an integral part of the municipality.

At the same time as he had asked for more autonomy, the organization's managing director had also proposed to build a new incineration plant exclusively for burning the waste of businesses, so that the organization could increase its share of this highly competitive market. The municipality granted this wish as well by deciding to build what was planned to be the most efficient waste incineration plant in the whole of Europe. ${ }^{1}$

In his new, more independent, and autonomous role, the organization's managing director adopted an entrepreneurial strategy aimed at making the organization more business-like. That meant rebranding the organization as a commercial "enterprise" by changing the word "agency" into "company" in its name, even though the organization remained part of the municipality. He also decided to hire a new financial and a new marketing director who both had earned their spurs in the business world and did not look at all in place in a more technical surrounding of a waste incineration plant. These two new directors, together with the managing director, were very critical about the organization and its employees and decided that a new organizational

\footnotetext{
${ }^{1}$ Building this plant turned out to be a financial and political disaster for the municipality, as it never worked properly.
} 
Fig. 3 The waste incineration organization after hybridization

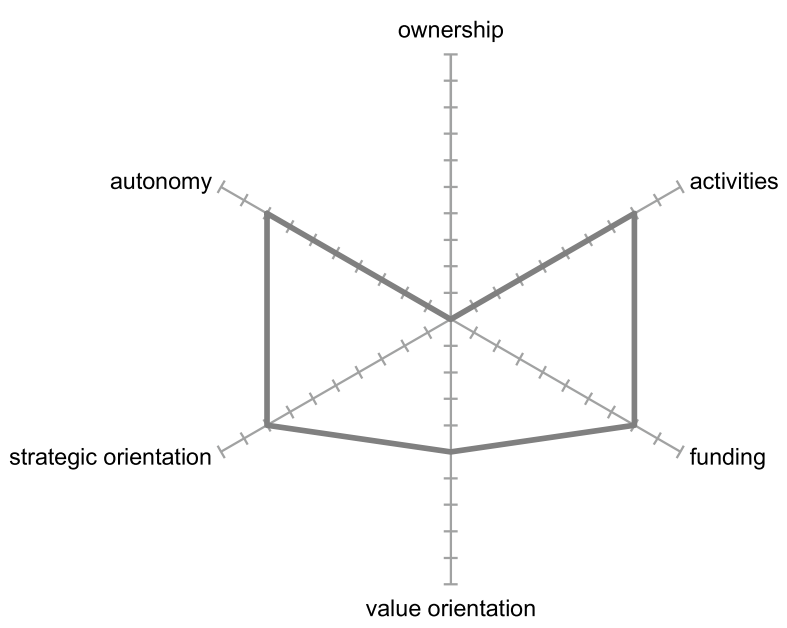

culture was needed which was more entrepreneurial. They also started to lobby the municipality for more managerial autonomy and a new status of the organization as an agency at arm's length from town hall, in order to be able to run the organization even more like a "normal" business entity.

Figure 3 shows how the organization scored on the six dimensions of the model after all these changes described before had been implemented. It still remained completely public with regard to its ownership, as that had not been changed. But with the building of its new plant, the organization was mostly focussed now on the commercial and highly competitive market for the incineration of business waste. Its value orientation was in the process to be changed and its strategic outlook already had. While he still technically fell under the purview of an alderman, the organization's managing director had now even more autonomy than before.

\section{Conclusions}

This article argued that public/private hybrid organizations mix the characteristics of state and market on several dimensions. Scoring an organization on these dimensions enables us to establish its hybrid thumbprint, which can be visualized using a radar chart. Analysing the hybrid thumbprint of an organization enables us to go beyond merely stating that an organization is hybrid and helps us to determine how it is hybrid.

The benefits of doing so are twofold. For one, understanding how an organization is hybrid can help us to subsequently discuss why it performs the way it does at a certain moment in time and to compare it and its performance to other organizations. This analysis and comparison not only helps us to understand hybridity better and to build better theories concerning this phenomenon but can also be used as management information by practitioners. 
A second benefit of the multidimensional model presented here is that it can also be used to look at organizations' hybrid character at various points in time, to analyse how their hybridity changed and to discuss whether and how this affected their performance in a positive or a negative way. This generates insights into the drivers behind the hybridization (and de-hybridization) of an organization during its life cycle.

Both uses of the multidimensional model were illustrated by looking at a hybrid organization operating in the Dutch waste management sector. The findings of this exercise suggest that even organizations close to government can already have some level of hybridity and that, even after an organization has been allowed to become more commercial by its political masters, it can be hybrid on some dimensions of the model and not on others. Scoring an organization using the multidimensional model showed that there is nothing like an ideal-typical hybrid organization, that scores evenly on all dimensions. On the contrary, each hybrid organization is unique and therefore its individual thumbprint has to be taken into account to be able to fully grasp its hybridity.

Based on the insights from this article, it would be fruitful to pursue further research aimed at fine-tuning the multidimensional model presented here by further specifying the dimensions, e.g., by asking different researchers to use them to study the same organization and/or to study different organizations in the same field or domain. Another avenue for further research is to delve deeper into the question how hybridity influences an organization's performance: what are the positive and negative effects of hybridity and how are they connected to the dimensions constituting an organization's hybrid thumbprint? For this it is necessary not only to generate more insight into hybridity's effects but to also link them to the dimensions used in the model presented in this article. This will again not only yield insight that can be used by theorists to build better models of hybrid organizations but also to practitioners, who have to deal with hybridity's positive and negative effects on an organization's performance day in day out.

\section{Declarations}

Informed Consent Informed consent has been obtained from all the respondents of the case study presented in Sect. 5.

Conflicts of Interest The author has no conflicts of interest or financial interests to declare.

Open Access This article is licensed under a Creative Commons Attribution 4.0 International License, which permits use, sharing, adaptation, distribution and reproduction in any medium or format, as long as you give appropriate credit to the original author(s) and the source, provide a link to the Creative Commons licence, and indicate if changes were made. The images or other third party material in this article are included in the article's Creative Commons licence, unless indicated otherwise in a credit line to the material. If material is not included in the article's Creative Commons licence and your intended use is not permitted by statutory regulation or exceeds the permitted use, you will need to obtain permission directly from the copyright holder. To view a copy of this licence, visit http://creativecommons.org/licen ses/by/4.0/. 


\section{References}

Alexius, S., \& Furusten, S. (2019). Exploring Constitutional Hybridity. In S. Alexius \& S. Furusten (Eds.), Managing Hybrid Organizations: Governance, Professionalism and Regulation (pp. 1-25). Springer International Publishing. https://doi.org/10.1007/978-3-319-95486-8_1

Anheier, H. K., \& Krlev, G. (2015). Guest Editors' Introduction. International Studies of Management \& Organization, 45(3), 193-206. https://doi.org/10.1080/00208825.2015.1006026

Battilana, J., \& Lee, M. (2014). Advancing research on hybrid organizing - insights from the study of social enterprises. The Academy of Management Annals, 8(1), 397-441. https://doi.org/10.1080/ 19416520.2014 .893615

Billis, D. (2010a). Hybrid organizations and the third sector: Challenges for practice, theory and policy. Palgrave Macmillan.

Billis, D. (2010b). Towards a theory of hybrid organizations. In D. Billis (Ed.), Hybrid organizations and the third sector: Challenges for practice, theory and policy (pp. 46-69). Palgrave Macmillan.

Billis, D., \& Rochester, C. (Eds.). (2020). Handbook on hybrid organisations. Edward Elgar Publishing.

Bozeman, B. (1987). All organizations are public: Bridging public and private organizational theories (1st ed.). Jossey-Bass.

Brandsen, T., \& Karré, P. M. (2011). Hybrid organizations: No cause for concern? International Journal of Public Administration, 34(13), 827-836. https://doi.org/10.1080/01900692.2011.605090

Brandsen, T., \& Karré, P. M. (2021). Hybridization and Hybridity. In R. A. List, H. K. Anheier, \& S. Toepler S. (Eds.), International Encyclopedia of Civil Society. Springer. https://doi-org.eur.idm.oclc. org/10.1007/978-3-319-99675-2_34-1.

Brandsen, T., van de Donk, W., \& Putters, K. (2005). Griffins or Chameleons? Hybridity as a permanent and inevitable characteristic of the third sector. International Journal of Public Administration, 28(9-10), 749-765. https://doi.org/10.1081/PAD-200067320

Brès, L., Raufflet, E., \& Boghossian, J. (2018). Pluralism in organizations: Learning from unconventional forms of organizations. International Journal of Management Reviews, 20(2), 364-386. https://doi. org/10.1111/ijmr.12136

Bruton, G. D., Peng, M. W., Ahlstrom, D., Stan, C., \& Kehan, Xu. (2015). State-owned enterprises around the world as hybrid organizations. Academy of Management Perspectives, 29(1), 92-114. https://doi.org/10.5465/amp.2013.0069

Christensen, T., \& Lægreid, P. (2010). Complexity and hybrid public administration-theoretical and empirical challenges. Public Organization Review, 11(4), 407-423. https://doi.org/10.1007/ s11115-010-0141-4

Christensen, T., \& Lægreid, P. (2011a). The Ashgate research companion to new public management. Ashgate.

Christensen, T., \& Lægreid, P. (2011b). Transcending new public management: The transformation of public sector reforms. Ashgate.

Dahl, R., \& Lindblom, C. E. (1953). Politics, economics and welfare planning and politico-economic systems resolved into basic social processes. Harper \& Row.

Defourny, J. (2014). From third sector to social enterprise: A European research trajectory. In J. Defourny, L. Hulgård \& V. Pestoff (Eds.), Social enterprise and the third sector. Changing European landscapes in a comparative perspective (pp. 17-41). Routledge.

Denis, J.-L., Ferlie, E., \& van Gestel, N. (2015). Understanding hybridity in public organizations. Public Administration, 93(2), 273-289. https://doi.org/10.1111/padm.12175

Fottler, M. D. (1981). Is management really generic? Academy of Management Review, 6(1), 1-12.

Geuss, R. (2001). Public goods, private goods. Princeton University Press.

Giauque, D., et al. (2014). The hybrid universe of public administration in the 21 st century. International Review of Administrative Sciences, 80(1), 23-32.

Grossi, G., Reichard, C., Thomasson, A., \& Vakkuri, J. (2017). Editorial. Public Money \& Management, 37(6), 379-386. https://doi.org/10.1080/09540962.2017.1344007

Hood, C. (1991). A public management for all seasons? Public Administration, 69(1), 3-19. https://doi. org/10.1111/j.1467-9299.1991.tb00779.x

Jacobs, J. (1992). Systems of survival: A dialogue on the moral foundations of commerce and politics (1st ed.). Random House.

Jay, J. (2012). Navigating Paradox as a mechanism of change and innovation in hybrid organizations. Academy of Management Journal, 56(1), 137-159. https://doi.org/10.5465/amj.2010.0772 
Johanson, J.-E., \& Vakkuri, J. (2018). Governing hybrid organisations: Exploring diversity of institutional life. Routledge.

Joldersma, C., \& Winter, V. (2002). Strategic management in hybrid organizations. Public Management Review, 4(1), 83-99.

Karré, P. M. (2011). Heads and tails: Both sides of the coin : an analysis of hybrid organizations in the Dutch waste management sector. Eleven International Publishing.

Lane, J.-E. (1994). Will public management drive out public administration? Asian Journal of Public Administration, 16(2), 139-151. https://doi.org/10.1080/02598272.1994.10800290

Mair, J., Mayer, J., \& Lutz, E. (2015). Navigating institutional plurality: Organizational governance in hybrid organizations. Organization Studies, 36(6), 713-739.

McLaughlin, K., Osborne, S. P., \& Ferlie, E. (2002). New public management: Current trends and future prospects. Routledge.

Osborne, D., \& Gaebler, T. (1992). Reinventing government: How the entrepreneurial spirit is transforming the public sector. Addison-Wesley Pub. Co.

Perry, J., \& Rainey, H. G. (1988). The public-private distinction in organization theory: A critique and research strategy. The Academy of Management Review, 13(2), 201, 182.

Pollitt, C., \& Talbot, C. (2004). Unbundled government: A critical analysis of the global trend to agencies. Routledge.

Pollitt, C., Talbot, C., Caulfield, J., \& Smullen, A. (2004). Agencies: How governments do things through semi-autonomous organizations. Palgrave Macmillan.

Pollitt, C., van Thiel, S., \& Homburg, V. (2007). New public management in Europe: Adaptation and alternatives. Palgrave Macmillan.

Powell, M., Gillett, A., \& Doherty, B. (2019). Sustainability in social enterprise: Hybrid organizing in public services. Public Management Review, 21(2), 159-186. https://doi.org/10.1080/14719037. 2018.1438504

Ragin, C. C. (2009). Fuzzy-set social science. University of Chicago Press.

Ragin, C. C. (2010). Redesigning social inquiry: Fuzzy sets and beyond. University of Chicago Press.

Rainey, H. G. (1997). Understanding and managing public organizations (2nd ed.). Jossey-Bass.

Rainey, H. G., \& Chun, Y. H. (2007). Public and private management compared. In E. Ferlie, L. E. Lynn, \& C. Pollitt (Eds.), The Oxford handbook of public management (1. publ. in paperback., pp. 72-102). Oxford Univ. Press.

Schmitz, B., \& Glänzel, G. (2016). Hybrid organizations: Concept and measurement. International Journal of Organizational Analysis, 24(1), 18-35. https://doi.org/10.1108/IJOA-07-2013-0690

Seibel, W. (2015). Welfare mixes and hybridity: Analytical and managerial implications: 'Welfare Mix' and hybridity: Divergent but compatible concepts. VOLUNTAS: International Journal of Voluntary and Nonprofit Organizations, 26(5), 1759-1768.

Skelcher, C., \& Smith, S. R. (2015). Theorizing hybridity: Institutional logics, complex organizations, and actor identities: The case of nonprofits. Public Administration, 93(2), 433-448.

Skelcher, C. (2005). Public-private partnerships and hybridity (E. Ferlie, L. E. Lynn, \& C. Pollitt, Eds.; pp. 347-370). Oxford University Press.

Smith, S. R. (2014). Hybridity and nonprofit organizations the research agenda. American Behavioral Scientist, 58(11), 1494-1508.

Thornton, P. H., Ocasio, W., \& Lounsbury, M. (2012). The institutional logics perspective: A new approach to culture, structure, and process. Oxford University Press.

Vakkuri, J., \& Johanson, J.-E. (Eds.). (2021). Hybrid governance, organisations and society: Value creation perspectives. Routledge.

Vakkuri, J., Johanson, J.-E., Feng, N. C., \& Giordano, F. (2021). Governance and accountability in hybrid organizations - past, present and future. Journal of Public Budgeting, Accounting \& Financial Management, 33(3), 245-260.

van der Wal, Z., \& van Hout, ETh. J. (2009). Is public value pluralism paramount? The intrinsic multiplicity and hybridity of public values. International Journal of Public Administration, 32(3), 220. https://doi.org/10.1080/01900690902732681

van der Wal, Z., De Graaf, G., \& Lasthuizen, K. (2008). What's valued most? Similarities and differences between the organizational values of the public and private sector. Public Administration, 86(2), 465-482. https://doi.org/10.1111/j.1467-9299.2008.00719.x

van Thiel, S. (2000). Quangocratization: Trends, causes and consequences. Interuniversity Center for Social Science Theory and Methodology. 
Wamsley, G., \& Zald, M. N. (1973). The political economy of public organizations: A critique and approach to the study of public administration. Lexington Books.

Publisher's Note Springer Nature remains neutral with regard to jurisdictional claims in published maps and institutional affiliations. 